ARTIGO

\title{
Avaliação, produção de conhecimento e formação de professores entre associações e rupturas
}

\author{
Amarildo Luiz Trevisan' (D) \\ Evandro Dotto Dias" (D) \\ lara da Silva Ferrão' (D)
}

\begin{abstract}
RESUMO
O texto procura investigar a relação entre o sistema de avaliação da Coordenação de Aperfeiçoamento de Pessoal de Nível Superior e a formação de professores no Brasil com base em uma filosofia da educação inspirada nas teorias de Habermas e Honneth. Interpreta o sistema de avaliação segundo a lógica que associa o binômio saber/poder de acordo com a produção de conhecimento do paradigma tecnológico moderno. Com isso, a ênfase recai sobre a competição por resultados, desconsiderando a imersão no processo colaborativo da produção. Acaba contribuindo assim para uma crescente instrumentalização do mundo da vida, na qual se ressalta o desenvolvimento do tecnicismo em todas as esferas da vida. A filosofia da educação contribui para indicar possíveis rupturas com esse modelo marcado pela demanda crescente, atrelada ao nexo produção-consumo, colaborando com a criação de uma sociedade democrática que acentua a responsabilidade em relação aos processos de construção da cidadania.
\end{abstract}

PALAVRAS-CHAVE

filosofia da educação; avaliação; formação de professores; saber; poder.

'Universidade Federal de Santa Maria, Santa Maria, RS, Brasil.

"Universidade Federal de Pelotas, Pelotas, RS, Brasil. 


\section{EVALUATION, KNOWLEDGE PRODUCTION AND TEACHER TRAINING AMONG ASSOCIATIONS AND RUPTURES}

\section{ABSTRACT}

The text seeks to investigate the relationship between the Coordenação de Aperfeiçoamento de Pessoal de Nível Superior (Coordination of Superior Level Staff Improvement) evaluation system and teacher education in Brazil, based on a philosophy of education inspired by the theories of Habermas and Honneth. It interprets the evaluation system according to the logic that associates the knowledge/power binomial according to the knowledge production of the modern technological paradigm. With this, the emphasis is on the competition for results, disregarding the immersion in the collaborative process of production. It thus contributes to a growing instrumentalization of the world of life, which highlights the development of technicality in all spheres of life. The philosophy of education contributes to indicate possible ruptures with this model marked by the growing demand, linked to the production-consumption nexus, collaborating with the creation of a democratic society that accentuates the responsibility in relation to the processes of construction of citizenship.

\section{KEYWORDS}

philosophy of education; evaluation; teacher training; knowledge; power.

\section{EVALUACIÓN, PRODUCCIÓN DE CONOCIMIENTO Y FORMACIÓN DE PROFESORES ENTRE ASOCIACIONES Y RUPTURAS}

\section{RESUMEN}

E1 texto busca investigar la relación entre el sistema de evaluación de la Coordenação de Aperfeiçoamento de Pessoal de Nível Superior (Coordinación de Mejora de Personal de Nivel Superior) y la formación de profesores en Brasil a partir de una filosofía de educación inspirada en las teorías de Habermas y Honneth. Interpreta el sistema de evaluación según la lógica que asocia el binomio saber/poder de acuerdo con la producción de conocimiento del paradigma tecnológico moderno. Con ello, el énfasis recae sobre la competición por resultados, desconsiderando la inmersión en el proceso colaborativo de la producción. En efecto, contribuye así a una creciente instrumentalización del mundo de la vida, en la que se resalta el desarrollo del tecnicismo en todas las esferas de la vida. La filosofía de la educación contribuye a indicar posibles rupturas con ese modelo marcado por la demanda creciente, ligada al nexo producción-consumo, colaborando con la creación de una sociedad democrática que acentúa la responsabilidad en relación a los procesos de construcción de la ciudadanía.

filosofía de la educación; evaluación; formación de profesores; saber; poder. 


\section{ASPECTOS INTRODUTÓRIOS}

No modelo da atual sociedade, no qual as relações interpessoais vêm sendo substituídas por produtos de consumo com uma urgência implacável, há uma inegável transformação do sujeito e do mundo em que vive. O resultado dessas transformações afeta a construção do sujeito moderno, especialmente em relação ao jovem e ao adolescente, os quais já nascem em um tempo em que as relações interpessoais são trocadas por produtos de fácil consumo. $\mathrm{O}$ mundo globalizado e a aplicação prática do conhecimento moderno têm um relacionamento muito próximo e conduzem a expectativa de uma sociedade voltada à produtividade e às questões tecnológicas do conhecimento. Nesse sentido, esses constructos não se restringem à função de dar sustentáculo às informações, mas influenciam a própria maneira de pensar e agir da sociedade.

A área educativa também é influenciada em sua produção de significados para atender às demandas genuínas desse tempo histórico. A formação do sujeito emancipado e a construção de valores em busca da cidadania trazem desafios à academia no que tange à composição da imagem docente. É por meio da construção de sentidos que estruturamos a sociedade e significamos a formação para a emancipação. Como participantes reflexivos e constituintes da construção social, a produção de saberes e a formação docente têm na ação comunicativa condições de contribuir para a emergência de novos valores, autonomia moral e também na elevação espiritual da sociedade. Portanto, torna-se imprescindível nesse processo formativo e investigativo docente deslindar as associações e rupturas entre as estruturas de produção, os processos avaliativos e a formação de professores do ponto de vista da educação como um bem comum partilhado por toda a sociedade.

A lógica da produção de conhecimento vem sendo associada historicamente ao binômio saber/poder. $\mathrm{Na}$ linha do tempo, podemos identificar, entre outras, a Igreja católica na Idade Média e as ciências naturais na Idade Moderna como legatárias dessa tradição. Será que o sistema de avaliação da pós-graduação no Brasil, pertencente à Coordenação de Aperfeiçoamento de Pessoal de Nível Superior (CAPES), pode ser considerado representante desse saber/poder no cotidiano das universidades atualmente? Ora, é claro que há um distanciamento entre as experiências de saber/poder da CAPES e o passado de predomínio quase exclusivo da Igreja na Idade Média e a eclosão da ciência na Idade Moderna, pois, enquanto estas se baseavam em critérios de verdade próprios de seu tempo, a CAPES possui uma estrutura de funcionamento constituída por pesquisadores que remete à escolha por seus pares. Porém, podemos supor, com base nessa lógica, que os profissionais experts escolhidos de maneira democrática não são totalmente livres para definir, com suas respectivas áreas, os critérios que valem para pautar a avaliação dos cursos. De acordo com nossa experiência no campo, observamos que eles têm de seguir uma lógica instrumental no sistema que os torna muitas vezes mais reféns do status quo vigente que protagonistas de um novo modelo avaliativo. Afinal, dentro das estatísticas do sistema CAPES, podemos historicamente perceber, por exemplo, a ênfase competitiva de avaliação baseada na comparação de performances acadêmicas. 
O que leva o Brasil a possuir um dos sistemas de avaliação da pós-graduação mais rigorosos e objetivos do mundo, o que, bem pelo contrário, não o isenta de críticas.

Desse modo, o conhecimento acadêmico e seu produtor, o pesquisador, estão perdendo a referência e a substancialidade para atribuição de uma métrica justificada pelas estruturas de publicação e circulação. Nesse contexto, podemos perceber a possibilidade da reificação e estreitamento na visão docente a partir de uma postura política de autoconservação pelo sistema competitivo. Portanto, para o docente entrar e manter-se no sistema é necessária a sua autorreificação. Mediante esse modelo de pesquisa formatado pela avaliação comparativa do sistema CAPES, questionamos: $O$ potencial de qualidade do pesquisador e do programa de pós-graduação não está dependente por demais da sua capacidade de adequação ao sistema avaliativo?

Diante disso, esta construção teórica apresenta as teorias de Jürgen Habermas e de Axel Honneth como uma contribuição para refletir sobre a produção de conhecimento e formação de professores no contexto da universidade, entendendo que as ações formativas e produtivas da área de educação são fundamentais para a criação de uma sociedade democrática, assim como a sua responsabilidade em relação aos processos de construção da cidadania. Assim, procuraremos compreender e repensar as associações e dissociações entre o sistema produtivo, a formação docente e o sistema de avaliação CAPES como fio condutor dessa reflexão, apresentando as preocupações de natureza político-educacional que podem ser potencializadas nas projeções dos discursos filosóficos desses autores.

\section{FORMAÇÃO DOCENTE E PRODUÇÃO ACADÊMICA}

Com base na visada de Jürgen Habermas (1968, 1999, 2004), buscamos referência para discutir os processos objetivos, subjetivos e intersubjetivos da formação de sujeitos mergulhados em suas ideias de mundo. Para Habermas, o conhecimento é dependente tanto do universo objetivo quanto do subjetivo, mas sempre condicionado à relação entre sujeitos que produzem esse saber. Nesse sentido, sem desconsiderar as diferenças no discurso, a verdade é produzida no consenso e tem na linguagem o seu principal canal de vivência e transmissão. A razão na percepção habermasiana apresenta-se como abertura de consenso livre e esclarecido e não como verdade imposta, ideal que deve ser buscado não apenas pela sua justificação diante de um público, mas é necessário referir a um contexto histórico específico e com propósitos definidos. Diante disso, nada é considerado justificável universalmente, se não for estabelecido consensualmente por meio da linguagem e da comunicação no confronto com o mundo da vida dos sujeitos envolvidos.

Portanto, para Habermas, existe uma relação entre razão, verdade e linguagem que se consolida na razão comunicativa e estabelece algo como verdadeiro quando há um consenso entre os membros dialogantes de uma comunidade linguística, porém resistente à prova do contato com o vivido. Mesmo que ele não trabalhe diretamente com o tema da formação de professores e da produção acadêmica, suas reflexões são de grande importância para a construção crítica dos discursos de excelência e formação do sujeito emancipado, no caso, o pesquisador: 
A unidade de investigação e ensino, entendida no seu sentido mais específico, significa que só se ensina e se aprende à medida das necessidades do processo inovador do progresso científico. A ciência deve também poder reproduzir-se a si própria, significando isto que os professores devem formar a sua própria descendência científica. O futuro investigador é o único objetivo em função do qual a universidade dos sábios investigadores assume tarefas formativas. (Habermas, 1993, p. 117)

A verdade, justificação e consenso têm assim uma interferência direta na maneira de produção do conhecimento e formação docente no âmbito universitário. No entanto, Habermas argumenta que o desenvolvimento da modernidade fez com que as ações pensadas como tradições que envolvem o coletivo foram colonizadas por aquelas voltadas ao atingimento do êxito via resultados práticos. Um exemplo está na maneira instrumentalizada de como a tecnologia é aceita como ideologia a ser consumida (Habermas, 1968), na qual o modelo de produção de ciência deve partir do processo de busca de inovações em forma de produtos para todas as áreas de conhecimento. Quando produzimos, na concepção moderna da economia, estamos sendo orientados para as necessidades materiais da sociedade, sendo elas colocadas não apenas como necessárias, e, sim, como imprescindíveis para a sobrevivência social e reprodução da vida, sem preocupação com a preservação do ecossistema humano e ambiental. Por isso é necessário para ele uma mudança paradigmática no próprio acontecer do projeto moderno:

Para além da crítica da racionalidade instrumental, amplamente fundamentada pelos teóricos frankfurtianos, em especial os estudos desenvolvidos por Adorno e Horkheimer na Dialética do Esclarecimento, Habermas entende que o sentido de emancipação da sociedade tal como originalmente formulado por Marx e também por Adorno e Horkheimer necessita ser repensado a partir de um novo paradigma explicativo. Assim, ele identifica o reducionismo a que foi submetida a razão moderna, na sua acepção cognitivo-instrumental, e propõe uma concepção de racionalidade mais ampla, com o objetivo de superar a característica manipuladora e objetivante das ações humanas, promovendo a crítica, e apontando possíveis saídas para as aporias da modernidade. (Gomes, 2007, p. 55)

Entre as aporias da modernidade, cumpre pensar o poder político do Estado que interfere diretamente na construção da cidadania e pode ser interpretado de diversas formas, entre elas o domínio das intenções avaliativas sobre as formativas e produtoras do conhecimento. Em tempos de grandes demandas produtivas da sociedade, a constituição do "ser" docente é permeada pelo contexto do mercado competitivo e políticas avaliativo-regulatórias de Estado. Os números e estatísticas demonstrados em rankings com notas de avaliação, que justificam as teorias desenvolvimentistas, demonstram o resultado como meta a ser obtida e determinada pela lógica macroeconômica da relação comparativa. Nesse contexto, a formação docente, mediante o pensamento crítico na produção do conhecimento acadêmico, 
encontra na universidade a possibilidade de alcançar os espaços humanos e sociais, ainda não contemplados pelo cientificismo tecnológico.

Com as ideias de Habermas nos sentimos absolutamente desafiados a pensar a possibilidade de uma teoria crítica da educação que reflita o caráter conflituoso e contingente da educação, a qual necessita, pela sua própria natureza, de um processo de reconstrução permanente das condições de formação de um sujeito emancipado. O caminho apontado por Habermas passa inevitavelmente pela reconstrução do projeto da modernidade, pois este nos fornece outras matrizes para instauração de um processo formativo que poderá proporcionar à sociedade uma vida mais justa, livre e feliz. (Gomes, 2007, p. 54)

Dessa forma, se a racionalidade cognitivo-instrumental modela a formação por meio do sistema de avaliação da CAPES e do Plano Nacional de Pós-Graduação (PNPG) (2011-2020) em demonstrativos estatísticos e justificações de excelência, podemos buscar inspiração no pensamento crítico e comunicativo para entender a intencionalidade manipuladora desses discursos no interior do ambiente universitário.

A universidade, enquanto instituição afeita tanto ao desenvolvimento do conhecimento científico-tecnológico quanto à formação de profissionais, que, de uma ou de outra forma, exercem liderança social, parece ser a instituição mais indicada para, de um lado, institucionalizar internamente e, de outro, fomentar o debate público destas questões. A universidade não sofre pelo excesso de ciência e técnica porque elas, efetivamente, promovem conforto e bem-estar. A universidade sofre, sim, da falta de pensamento crítico que alcance os espaços humanos e sociais, que ciência e tecnologia sozinhas não alcançam. (Goergen, 2014, p. 582)

Com base nesses conceitos, somos instigados à crítica dessa lógica (cognitivista e instrumental) presente nos processos formativos dos sujeitos na universidade, passando obrigatoriamente pela educação e a sua necessidade de reconstrução por meio da linguagem em relação aos rumos da emancipação, sendo nesse sentido a perspectiva teórica de Habermas.

$\mathrm{Na}$ sua concepção, a linguagem apresenta um telos de entendimento que possibilita uma integração entre o mundo social, objetivo e subjetivo. Com tais ideias desenvolve o conceito de Racionalidade Comunicativa, a partir das pretensões de validade das interações linguísticas, que nos permitem pressupor a formação de consensos, livres de qualquer tipo de coerção. (Gomes, 2007, p. 54)

Mas será que a formação de professores, baseada na dimensão macroeconômica atual, consegue escapar à determinação instrumental reificadora da sociedade e seu consequente processo de estreitamento reflexivo? Para Goergen, "aos poucos, a educação superior abandonou seus ideais formativos, integrando-se, em termos de pesquisa e ensino, ao grande movimento da tecnociência em prejuízo de sua autonomia no pensar" (Goergen, 2014, p. 575). Esse modelo intensivo e reducionista parece 
conduzir a academia a um processo de "esquecimento do reconhecimento" e de sua universalidade como conhecimento acadêmico gerado com intuito de promover a formação emancipatória em detrimento da reificação produtiva. A compreensão da complexidade do agir docente é orientada pela interpretação da realidade acadêmica aliada à intersubjetividade e autocompreensão das vocações do ser docente na busca de uma melhor orientação hermenêutica.

Mas, quando as regras metodológicas unem deste modo a interpretação com a aplicação, então sugere-se a interpretação de que investigação hermenêutica a abre à realidade, sob a guia do interesse pela conservação e ampliação da intersubjetividade de uma possível compreensão orientadora do agir. A compreensão de sentido dirige-se, segundo a sua estrutura, para o possível consenso dos agentes no âmbito de uma autocompreensão transmitida. Chamamos a isto diferentemente do técnico, o interesse prático do conhecimento. (Habermas, 1968, p. 139)

$\mathrm{Na}$ visão de Gomes, o consenso habermasiano "como critério de validação do pensar e do agir, fundamentado pela busca cooperativa e processual da verdade, nos permite conceber a ideia da possibilidade de um processo de ‘desbarbarização' das relações sociais” (Gomes, 2007, p. 60). Portanto, pode-se caracterizar como uma perspectiva de emancipação por meio da racionalidade comunicativa, ao perceber que a modernidade ainda pode seguir seu caminho em busca da libertação do domínio heterônomo, que é um ideal presente na matriz do pensamento moderno, segundo Habermas (1999). E isso é possível à medida que a educação assumir o seu papel fundamental e contribuinte na reversão da colonização do mundo da vida pelo mundo sistêmico do trabalho, mediante o uso da linguagem e do aperfeiçoamento de suas ações em um processo cooperativo de aprendizagens que buscam a emancipação via processos democráticos.

Como educadores e pesquisadores (formado-formadores), é possível alcançar a cooperação acadêmica visando a estabelecer "uma mudança de paradigma [...] principalmente porque o que passa a prevalecer (dentro desta visão) não é mais a verdade proposicional, e, sim, a busca cooperativa da verdade" (Gomes, 2007, p. 5). É nesse contexto que buscamos uma concepção avaliativa do sistema da pós-graduação com a prevalência inspirada na proposta habermasiana de abordagem colaborativa, buscando a obtenção de convicções intersubjetivas baseadas em critérios que visam aos melhores argumentos. Desse modo:

Também estas investigações perseguem um interesse cognitivo hermenêutico; permitem, com efeito, confrontar as instituições sociais dadas e a sua autocompreensão com as técnicas efetivamente utilizadas e com aquelas de que possivelmente se poderá vir a dispor; e, em relação semelhante com esta clarificação que visa a uma crítica da ideologia, elas permitem, inversamente, reorientar também as necessidades sociais e os objetivos explícitos. (Habermas, 1968, p. 120) 
Podemos questionar, entretanto, se, em relação ao sistema CAPES de avaliação, não há uma atenção exagerada à validade do argumento da excelência acadêmica por si só, deixando de lado o impacto desse discurso na realidade ou a sua legitimidade nas práticas bem-sucedidas diante de um mundo que nos é comum. Afinal, os ataques sofridos pelas universidades no Brasil hoje, com cortes de verbas e acusações de doutrinação ideológica, demonstram quanto é necessário buscar essa articulação da pós-graduação com as necessidades do mundo vivido, e não apenas voltado à lógica avaliativa do sistema. Os protestos em defesa da universidade e manutenção do seu controle público não podem descurar a necessidade de aperfeiçoamento desse processo, caso contrário o mundo da vida continuará colonizado por um ideário preconceituoso, anticientífico e beligerante. Como Habermas (2004, p. 59) afirma: "a verdade que alegamos para uma proposição aqui e agora, no nosso contexto e na nossa linguagem, deve transcender qualquer contexto dado de justificação". E isso gera uma preocupação com o quanto de verdade está contemplado no discurso da excelência acadêmica desvinculado da prática da vida, inclusive no planejamento educacional (PNPG 2011- 2020). Ou, então, se não é possível outra via de entendimento dessa questão, na linha do que o próprio Habermas (2004, p. 66-67) acena:

Esse fracasso exige uma série de processos de aprendizado pelos quais as partes conflitantes chegam a descentralizar as suas perspectivas egocêntricas e etnocêntricas de tal modo que possam incluir-se reciprocamente uma à outra na construção conjunta de um mundo mais amplo de relações interpessoais legítimas.

Ainda segundo Habermas, no mundo prático precisamos contar com conviç̧ões não problemáticas que nos permitam nele agir sem questionamentos. Porém, "a 'verdade' é um conceito que transcende toda a justificação e também não pode ser identificado com o conceito de assertibilidade idealmente justificada. As condições de verdade devem ser preenchidas pela própria realidade"(Habermas, 2004, p. 279-280). Assim, tudo o que for justificado em um grupo comunicativo deve ser traduzido para a esfera da ação, pois esta é que vai atestar a legitimidade prática do que foi acertado. Para o autor, "o que importa ao mundo da vida é o papel de uma verdade bifronte, que serve de intermediária entre a certeza da ação e a assertibilidade discursivamente justificada" (Habermas, 2004, p. 249).

No entanto, a racionalidade instrumental, para Goergen (2014), está presente no "sangue que circula nas veias" do Estado dentro de uma mentalidade economicista, que pressiona a produção do conhecimento à adaptação produtiva para a obtenção de manutenção de atividades de pesquisa e recursos.

No interior da universidade, as decisões relativas ao planejamento curricular, à criação de novas disciplinas e projetos de pesquisa e estudo se orientam crescentemente no interesse instrumental. Inclusive as instituições de fomento consideram esta variante como critério importante para a concessão de recursos. Este é o círculo vicioso cada vez mais difícil de ser rompido. Pelo que vemos, a universidade não resiste à pressão adaptativa de ajustar-se às regras 
da gramática da racionalidade instrumental. O sangue que circula nas veias do próprio Estado está contaminado por esta mentalidade instrumental/economicista contaminando as instituições públicas. (Goergen, 2014, p. 578)

O Estado-avaliador exerce a "pressão produtiva e adaptativa" às suas regras de controle da produção científica e tecnológica pelo crescente interesse instrumental na produção da academia. Sendo assim, a legitimidade da avaliação e suas contribuições concretas para a formação e produção científica da área acabam sendo comprometidas com esse círculo vicioso. $\mathrm{E}$, além disso, a preocupação com a efetiva mudança desse quadro está bloqueada porque o sistema se justifica ou se basta a si próprio, independentemente das demandas do entorno vivido.

\section{FORMAÇÃO OU REIFICAÇÃO?}

Seguindo a análise desenvolvida até o presente, vamos procurar entender a reificação da produção acadêmica com base na teoria do reconhecimento de Axel Honneth, ${ }^{1}$ com vistas a melhor interpretar a relação da perda das qualidades humanas que daí decorre pela naturalização da disputa por resultados. Como eixo teórico desse tema, buscamos as referências principais em seu livro Reificación: un estudio en la teoría del reconocimiento (2007) e no artigo "Observações sobre a reificação" (2008). Nesses aportes, Honneth faz uma releitura do conceito de reificação baseado em Lukács (2003), recuperado da obra O capital, de Karl Marx. Nessa nova leitura, Honneth busca também a inspiração hegeliana, procurando distanciar-se da interpretação tradicional do materialismo marxista e da ontológica separação sujeito e objeto, que está presente dentro da concepção da filosofia moderna.

A filosofia social moderna pisa a arena num momento da história das ideias em que a vida social é definida em seu conceito fundamental como uma relação de luta por autoconservação; os escritos políticos de Maquiavel preparam a concepção segundo a qual os sujeitos individuais se contrapõem numa concorrência permanente de interesses, não diferentemente de coletividades políticas; na obra de Thomas Hobbes, ela se torna enfim a base de uma teoria do contrato que fundamenta a soberania do Estado. Ela só pudera chegar a esse novo modelo conceitual de uma "luta por autoconservação" depois que os componentes centrais da doutrina política da Antiguidade, em vigor até a Idade Média, perderam sua imensa força de convicção. (Honneth, 2003, p. 31)

Diferente dessa visão moderna, Hegel esboçou a possibilidade de os seres humanos estabelecerem outras relações que não apenas se baseiem na conflitualidade

1 Axel Honneth é seguidor da teoria crítica e atual presidente do Instituto para a Pesquisa Social, popularmente conhecido como Escola de Frankfurt, tendo como mentor Jürgen Habermas. Honneth $(2003$, p. 63) trata do assunto do reconhecimento em sua obra Luta por reconhecimento: a gramática moral dos conflitos sociais, por intermédio da visão hegeliana do "reconhecer-se-no-outro". 
da autoconservação, mas também na luta pelo reconhecimento social. Nesse movimento, a intersubjetividade apresenta-se como identidade dentro de um fator no qual a sociedade e a tensão moral buscam uma condição de liberdade para além do simples enfrentamento:

Hegel defende naquela época a convicção de que resulta de uma luta dos sujeitos pelo reconhecimento recíproco de sua identidade uma pressão intrassocial para o estabelecimento prático e político de instituições garantidoras da liberdade; trata-se da pretensão dos indivíduos ao reconhecimento intersubjetivo de sua identidade, inerente à vida social desde o começo na qualidade de uma tensão moral que volta a impelir para além da respectiva medida institucionalizada de progresso social e, desse modo, conduz pouco a pouco a um estado de liberdade comunicativamente vivida, pelo caminho negativo de um conflito a se repetir de maneira gradativa. (Honneth, 2003, p. 29)

Hegel é uma referência não apenas para Honneth, mas de resto para todos os integrantes do Instituto para a Pesquisa Social (Escola de Frankfurt). Para Adorno, por exemplo, a verdade dever ser buscada para além do conceito de substância, sendo assim, como o sujeito hegeliano, capaz de elaborações e reelaborações da relação com o passado.

"O passado não é um ponto fixo" do qual deriva o presente, dissera Walter Benjamin. Caberia conferir um sentido à história reelaborando a relação do passado ao presente, justamente para apreender o presente como sentido histórico, acessível a uma práxis transformadora. "A verdade, o absoluto, não apenas como substância, mas como sujeito”, diria Hegel. (Adorno, 1995, p. 24)

A educação para Adorno, como alternativa da semiformação, é orientada para a autorreflexão crítica e emancipatória, que demonstra uma composição racional entre o sujeito e a coisa e suas relações formadoras e transformadoras, individuais e coletivas. Desse modo, as coisas em si devem buscar seu significado na relação sujeito-sujeito, entre suas relações e verdades, e não na determinação da coisa-sujeito (reificado), que, como veremos melhor logo adiante, acontece atualmente na tendência meramente instrumental e coisificadora da macroeconomia, que, por sua vez, influencia os rumos da educação.

De posse da compreensão desse núcleo argumentativo a respeito das relações humanas, Honneth passa à diferenciação dos conceitos de instrumentalização, utilizado por Habermas e a Escola de Frankfurt, e o de reificação, na acepção que ele retoma. A princípio, concorda com Habermas a respeito da subdivisão entre mundo da vida e sistema. Nesse sentido, para Honneth (2003, p. 14):

a distinção de Habermas entre "sistema" " "mundo da vida" veio responder, portanto, à exigência de um conceito de racionalidade complexo, em que a racionalidade instrumental passa a ser limitada, de modo a não sufocar e obscurecer as estruturas comunicativas profundas presentes nas relações sociais. Trata-se de 
um conceito de sociedade em dois níveis, em que a reprodução material é obtida essencialmente por mecanismos de coordenação da ação tipicamente instrumentais (cuja lógica caracteriza o domínio social do "sistema"), e em que a reprodução simbólica depende de mecanismos comunicativos de coordenação da ação (cuja lógica caracteriza o "mundo da vida").

A reprodução material é tida como resultado, mas o movimento como um processo é o que caracteriza os mecanismos comunicativos do desenvolvimento social no mundo da vida. Porém, Honneth acentua que, "diferentemente da instrumentalização, a reificação pressupõe que nós nem percebamos mais, nas outras pessoas, características que as tornam propriamente exemplares do gênero humano" (Honneth, 2008, p. 70). Portanto, pressupõe "tratar alguém como coisa significa [...] despido de quaisquer características ou habilidades humanas" (Honneth, 2008, p. 70). A "instrumentalização", na concepção do autor, "significa tomar outras pessoas como meio para fins puramente individuais, egocêntricos" sem, no entanto, "precisarmos abstrair de suas características humanas; ao contrário, geralmente serão inclusive as habilidades especificamente humanas dessas pessoas que utilizamos para, com sua ajuda, realizar nossos propósitos"(Honneth, 2008, p. 70). A reificação é principalmente o esquecimento do reconhecimento ou do autorreconhecimento, sendo que o processo de perda das qualidades humanas torna-se um comportamento naturalizado dentro de uma ideologia que sem dúvida é regressiva. Assim, enquanto Habermas percebe a necessidade de abrir a razão para outras dimensões do conhecimento, incorporando as demandas e preceitos do mundo da vida, Honneth percebe que a própria ideia de racionalidade instrumental deveria ser revista pela perspectiva da coisificação do ser humano. Dessa diferenciação surge o conceito de reificação, no sentido negativo, qual seja: "um atentado contra pressupostos necessários de nosso mundo socialmente vivido" (Honneth, 2008, p. 70). E por isso ele tem a ver com a dimensão moral, pois a reificação está na base da instrumentalização, significando o modo ontologicamente inapropriado de lidar com seres humanos. A partir da atitude original de não reconhecimento do outro como um ser digno de valor e liberdade é que a racionalidade instrumental se vale das qualidades especificamente humanas para subjugar o outro a seus propósitos.

Ao se indagar sobre o que o despertou para o tema, Honneth percebe que foi o fenômeno da barbárie, aceito como um modus operandi na formação de um povo.

Contudo, se eu me pergunto qual era o fenômeno que originalmente despertou meu interesse pelo tema da reificação, então preciso admitir que possivelmente tenha sido a dificuldade de uma explicação para o genocídio "industrializado". Até hoje é difícil compreender os relatos nos quais é mostrado como jovens homens, aparentemente sem nenhuma comoção, matavam centenas de crianças e mulheres judias com um tiro na nuca (Browning, 1998); e elementos de tal práxis horrível podem ser encontrados em todos aqueles genocídios dos quais o final do século 20 estava impregnado [...] então tais genocídios colocam-nos diante da pergunta, como devemos explicar o desaparecimento, o "esquecimento", do reconhecimento previamente concedido. (Honneth, 2008, p. 69) 
Além do genocídio dos campos de concentração, ao longo de seus textos, Honneth cita outros exemplos em que ocorrem os processos de reificação. Entre eles, "os atos de guerra como nós os conhecemos da apresentação estética em filmes e romances" (Honneth, 2008, p. 76), os quais apresentam exemplos contundentes da concepção de reificação. Nesse contexto, "a destruição do adversário se autonomiza a tal ponto, que mesmo na percepção de pessoas não participantes (crianças, mulheres) gradativamente se perde toda a atenção para suas características humanas" (Honneth, 2008, p. 76). Portanto, presume-se que os inimigos "são considerados apenas como objetos inanimados, coisificados, face aos quais a morte ou a violação são justificadas sem dificuldade" (Honneth, 2008, p. 76). De acordo com essa concepção, "parece-me ter sido apagado completamente qualquer rasto de ressonância existencial, a tal ponto que não podemos falar simplesmente de indiferença ou ódio emocional, mas sim de reificação" (Honneth, 2008, p. 76).

Por meio dessa característica produtivo-coisificante ocorre o esquecimento do reconhecimento do sujeito em virtude do incentivo à concorrência. Sendo assim, torna-se necessária a autoconservação em relação ao processo de ampliação de poder para evitar o ataque competitivo do outro, o que pode levar a uma compreensão estreita do patamar de relações interpessoais na academia.

Esse comportamento por antecipação se exacerba, porém, no momento em que o ser humano depara com um próximo, tornando-se uma forma de intensificação preventiva do poder que nasce da suspeita; uma vez que os dois sujeitos mantêm-se reciprocamente estranhos e impenetráveis no que concerne aos propósitos de sua ação, cada um é forçado a ampliar prospectivamente seu potencial de poder a fim de evitar também no futuro o ataque possível do outro. (Honneth, 2003, p. 34)

A educação e a produção social estão definidas pelas ações políticas, na medida em que atualmente a autoconservação é um objetivo individual e coletivo acima de qualquer outro, convergindo para a sobrevivência da estrutura competitiva. Para Lukács (2003, p. 200), "a universalidade da forma mercantil condiciona, portanto, tanto sob o aspecto objetivo quanto sob o subjetivo, uma abstração do trabalho humano que se objetiva nas mercadorias". Nessa interpretação reificada, a relação sujeito-objeto fica caracterizada na visão de inspiração materialista do autor, na qual o sujeito é desvirtualizado de sua essência intersubjetiva quando a significação do objeto é tirada de sua esfera de atuação, atribuindo-lhe "vida própria". Sendo assim, é qualificada apenas a substância na visão hegeliana, na medida em que, para Lukács (2003, p. 201):

a forma mercantil só se torna possível como forma da igualdade, da permutabilidade de objetos qualitativamente diferentes pelo fato de esses objetos - nessa relação que é a única a lhes conferir sua natureza de mercadorias — serem vistos como formalmente iguais.

Ainda na concepção de Lukács, há uma referência ao caminho percorrido pelo histórico de desenvolvimento do processo de trabalho, no seu processo de 
racionalização e intensificação. Essa perspectiva é embasada em cálculos racionais como sua referência, dentro da quantidade de trabalho objetivamente calculável que se acaba opondo ao trabalhador sob a forma de uma objetividade pronta e estabelecida, isto é, o resultado. Portanto, o mundo do trabalho já convive com a eliminação cada vez maior das propriedades qualitativas, humanas e individuais do trabalhador.

Para a consciência reificada, essas formas de capital (capital mercantil, função do dinheiro como tesouro ou como capital financeiro, etc.) se transformam necessariamente nos verdadeiros representantes da sua vida social [...] a ponto de se tornarem completamente imperceptíveis e irreconhecíveis as relações dos homens entre si e com os objetos reais, destinados à satisfação real de suas necessidades. [...] Sendo assim, para a consciência reificada, esta se torna, necessariamente, a forma de manifestação do seu próprio imediatismo, que ela, enquanto consciência reificada, não tenta superar. Ao contrário, tal forma tenta estabelecer e eternizar esse imediatismo por meio de um "aprofundamento científico” dos sistemas de leis apreensíveis. (Lukács, 2003, p. 211)

Tal como acontece hoje com o império do mercado de capitais e as bolsas de valores, que decidem as reformas a serem realizadas no mundo humano e do trabalho, ocorre igualmente com a concepção do fenômeno da reificação, em que impera a separação do produtor dos seus meios de produção, que acabam sendo elevados como verdadeiros sujeitos do processo. Em consequência, as relações originais (as relações humanas) são substituídas por relações racionalmente reificadas. E isso "significa que o princípio da mecanização racional e da calculabilidade deve prioritariamente abarcar todos os aspectos da vida" (Lukács, 2003, p. 207). Essa inversão é atribuída ao próprio reconhecimento pelo sistema capitalista, na medida em que, como Honneth critica:

Como um todo, o sistema da economia capitalista mediado pelo mercado se apoia motivacionalmente no fato de que será atribuída aos seus membros a respectiva medida de reconhecimento que corresponder à intensidade meritocrática de suas contribuições individuais para a produção através da divisão do trabalho. (Honneth, 2014, p. 160)

Os interesses de desenvolvimento acadêmico devem alavancar o desenvolvimento econômico em que medida? Será que, além de reificados, não estamos também sendo colonizados na investigação acadêmica pelas políticas econômicas globalizadas, tendo como fim justificado a excelência produtiva? Na visão de Honneth, a partir de Sartre, o colonialismo se caracteriza como uma deformação das "relações intersubjetivas do reconhecimento mútuo", sendo que degradam sistematicamente os nativos colonizados em relação às suas qualidades humanas.

Se essas considerações de Sartre parecem bastante artificiais ou mesmo toscas, a chave interpretativa da teoria da comunicação que ele coloca em sua base tem 
todo o interesse para fins empíricos: os padrões de comunicação assimétrica do tipo que existe entre invasor e nativo no sistema colonial representam para ele relações interativas que requerem dos dois lados a negação e a preservação simultâneas de relações de reconhecimento recíproco. (Honneth, 2003, p. 248)

Para contextualizar a reificação na formação docente pela pesquisa acadêmica em seu modelo avaliativo-competitivo, podemos nos perguntar: É necessário que o sistema de regulação do Estado determine o "valor" e, se necessário, o "rigor mortis" da produção científica dos pesquisadores e seus programas? Na verdade, há uma métrica a ser seguida que funciona como uma base reificadora, permitindo aos programas de pós-graduação executar a instrumentalização do professor e do estudante. A "música" que a CAPES quer ouvir é baseada na produção de artigos B2 para cima, isto é, se o curso quer se manter entre os patamares de avaliação 3 e 4 , necessários para a manutenção do seu funcionamento, o B2 tem muita importância. Mas, se ele quiser alcançar o conceito 5 , então vale mais investir na classificação de artigos B1 para cima. $\mathrm{E}$, se o curso quiser ou pretende manter-se nos patamares 6 ou 7, então valem mais os artigos de excelência, os quais têm a duração de um quadriênio. Assim os programas já estruturam seus regimentos influenciados diretamente pelo que a CAPES compreende por produto qualificado na área. Por isso a formação de professores vem promovendo ações que, de alguma maneira, requerem o conhecimento como um artifício que carrega consigo a efemeridade da sociedade da produção-consumo, desconsiderando aspectos como a repercussão e permanência do "produto" no âmbito da intersubjetividade.

Cumpre salientar que os objetivos qualisados de produção não valorizam o conhecimento em si produzido pelo pesquisador na academia. O periódico ou a editora no qual esse conhecimento está depositado é que captura o conceito. Portanto, o produto tem de ser aceito pela estrutura de status como sendo de excelência acadêmica, ou rejeitado por não se enquadrar no perfil desejado pela avaliação do periódico ou da editora. $\mathrm{O}$ conhecimento produzido, mesmo sendo uma possibilidade de verdade social, pode não ter valor produtivo para o sistema CAPES.

A competitividade incentivada pelo modelo avaliativo já está absorvida na cultura da academia. Essa postura impõe a autopreservação acadêmica aos propósitos de investigação do pesquisador. A produção intensiva de conhecimento é necessária para a manutenção do funcionamento dos programas, assim como para a comparação de status entre os programas de pós-graduação no ranking da CAPES. Como não poderia deixar de ser, esse comportamento está sendo incorporado na formação docente como um processo naturalizado de sobrevivência dos programas, dos pesquisadores e dos estudantes para o atingimento de suas metas de pesquisa.

$\mathrm{Na}$ academia, pensamos e replicamos nossos conhecimentos (por imposições de regulação e fomento) sem a possibilidade de defender a nossa própria constituição na formação cultural (Bildung). ${ }^{2}$ Buscamos, possivelmente, o cumprimento

2 A referência ao conceito de formação cultural pela sua relação com o clássico, que resiste aos tempos, é pensada em antítese à efemeridade dos tempos atuais. 
de metas por meio de métodos e normas dentro de um possível processo de autorreificação. Sendo assim, a pesquisa e os pesquisadores podem ser caracterizados como uma área explorada pelo capital com verdadeira "colonização acadêmica" de intenções economicistas.

A racionalidade do sistema avaliativo não pode, necessariamente, silenciar a voz docente à produção material, direcionando-a para mecanismos de coordenação do conhecimento na academia. Pela ótica da visão técnico-científica instrumentalizada, os resultados na pesquisa em educação podem ser considerados "fracos" por não estarem alinhados com o ponto de vista exclusivamente utilitarista. Atualmente é necessária a padronização numérica na formatação do seu "produto final" com seu potencial de mercado para a quantificação da produção do conhecimento e sua comparação competitiva no modelo CAPES.

É claro que percebemos avanços, como a incorporação nos últimos tempos de critérios de avaliação que levam em consideração os impactos sociais da pesquisa, bem como a capacidade de auxiliar programas que estão geograficamente distantes mediante a oferta do programa MINTER e DINTER - Mestrado ou Doutorado Interinstitucional. Portanto, apesar das dificuldades operacionais do sistema (corte de recursos e bolsas, não seguimento das escolhas de reitores de universidades, retirada de recursos das agências de fomento e pesquisa), não há dúvidas de que o sistema tem avançado também no sentido qualitativo. A qualidade dos "produtos" tem aumentado e por isso esse modelo permanece, pois encontra ressonância não apenas no aprimoramento da formação de quadros, mas também no maior incremento do próprio funcionamento dos programas e na qualidade da produção.

No entanto, o que chamamos atenção aqui diz respeito ao modelo quantitativo, que se torna predominantemente instrumentalizado, a ponto de o pesquisador produzir o saber e ficar refém da estrutura avaliativa para a "pesagem" e publicação desse conteúdo. Diante disso, as propriedades qualitativas do conhecimento e do seu produtor-trabalhador são secundarizas, assim como seu significado intersubjetivo e social. A filosofia que sustenta a manutenção de uma estrutura avaliativa fixa torna-se a parte mais importante do processo de pesquisa e publicação das atividades dos programas de pós-graduação.

\section{ASPECTOS FINAIS}

O planejamento de metas e a avaliação são extremamente necessários para os programas de pós-graduação, mas devemos salientar o fim que é proposto nesse sistema. A filosofia da educação, ao se indagar sobre o para que ensinar, como já salientava Adorno (1995), busca evitar ou não reproduzir a barbárie social. Mediante a concepção atual do sistema, nesse ambiente comparativo e competitivo, os programas e pesquisadores são traduzidos numericamente como potenciais "produtos" e "produtores". Entretanto, a formação e a avaliação das performances na pesquisa em educação são mais abrangentes do que um conjunto de variáveis matemáticas; é também, um processo formativo que envolve aspectos culturais e político-sociais.

Essas políticas têm o intuito de produzir para o atendimento da lógica do mercado, em vez de responder a processos que podem permitir ao docente e ao 
estudante o questionamento e a discussão dos paradoxos em relação a sua formação de pesquisador. Atualmente, a educação convive com seus dilemas avaliativos na pesquisa acadêmica, influenciando a construção da identidade pesquisador-docente. Esse paradigma da produção de conhecimento e formação de educadores é direcionado e ranqueado para o atendimento das demandas político-econômicas do Estado e sua inserção macroeconômica.

A formação dos formadores transita, necessariamente, como um pré-requisito obrigatório na pesquisa acadêmica. $\mathrm{O}$ docente pesquisador é formado também pela produção do conhecimento gerado pela sua pesquisa. Torna-se necessário salientar que tal produção contribui para tornar público o que a academia produz. Mas a formatação do seu conteúdo com a orientação para a modelagem produtiva pode plasmar a formação docente no sentido único de produção do conhecimento útil. Esse constructo instrumentalizado é de grande interesse empresarial e de pouco impacto social, pois transita no mercado para chegar à sociedade, portanto, agregando preço e tornando-se de alto custo para a maioria da população brasileira.

Ocorre, como diz Hegel, que "o número é precisamente a determinidade de todo inerte, indiferente e morta na qual todo movimento e relacionamento se extinguem; e que rompeu a ponte [que a unia] com a vitalidade dos impulsos, com os hábitos, tipo de vida e com todo o ser-aí sensível” (Hegel, 1992, p. 184). Nesse sistema numérico e competitivo, nasce a hierarquia de excelência na qualidade da produção acadêmica que serve como um alinhamento econômico às metas do Estado. Nesse caso, a avaliação com características predominantemente quantitativas leva consigo as características da reificação e da autorreificação na formação e na imagem docente. Isso se dá pelo fato de que é necessário obter o quantitativo científico suficiente para o olhar CAPES, a fim de manter o funcionamento dos programas atrelado ao sistema. Assim, o pesquisador-docente é reificado à produção do objeto-investigação, em detrimento da significação da formação como sujeito-docente-pesquisador.

Diante dessa lógica, ascende a crença de Habermas e Honneth de que há uma crescente instrumentalização e coisificação no mundo da vida, que impulsiona o desenvolvimento do tecnicismo em todas as esferas, inclusive educacional. E isso acaba reproduzindo a lógica do sistema em prejuízo do mundo da vida, obliterando espaços da linguagem, do sentido e da liberdade.

A área da Educação pode contribuir decisivamente para o desenvolvimento da pesquisa brasileira, sendo uma voz crítica em relação a essa preponderância da avaliação comparativa (dita científica) que coloniza as humanidades. Portanto, em vez do resultado, a avaliação deve entender também a necessidade de conferir maior espaço para a construção do processo formativo e sua relevância social. Nesse aspecto, tal constructo deve ser amplo e colaborativo, buscando a maior valorização do sujeito no enfrentamento dos graves problemas sociais do país, no planejamento da pesquisa e de seu fomento.

Diferente disso, a partir da instrumentalidade da relação do conhecimento científico e seu produtor, ocorrido pelas influências da economia nos conceitos de formação, podemos perceber que a experiência formativa está em um processo de adequação cada vez maior à avaliação das políticas de gerenciamento do Estado. 
As determinações propostas pelo discurso da avaliação com base na tecnologia criam o estranhamento entre ciência, técnica e humanidade. Portanto, a constituição da formação acadêmica do docente-pesquisador torna-se pesquisador-docente, na medida em que o sujeito é determinado pelo produto de sua pesquisa.

Os caminhos das investigações científicas em seus movimentos criativos são impregnados por significações humanas. A ideia que sustentou este trabalho tem relação direta com o sistema de avaliação colaborativo proposto, o qual envolve a subjetividade do sujeito, isto é, a sua capacidade de ser autônomo e não ficar preso às malhas da reificação sistêmica e mercadológica. Mas na visão atual, embora haja avanços, o sujeito ainda é negligenciado. Para tanto, a autoconsciência, o reconhecimento do outro, a própria relação individual e coletiva da produção é coisificada pelo olhar da avaliação, o qual já tem a estrutura da modelagem dada de forma anterior ao vivido, tornando-se assim, de certa forma, também responsável pelo descalabro que estamos vivendo na esfera pública atualmente. Afinal, a voz e a atuação do pesquisador estão direcionadas desse modo para a manutenção do sistema avaliativo, e não para a transformação das precárias condições de vida das populações, predominantemente.

A formação da autoconsciência deve buscar incentivar no sujeito a opinião crítica aos modelos que, pela necessidade exacerbada de produtividade, buscam a redução aos interesses da economia, chegando assim à reificação do ser e do saber nos objetivos do PNPG para a academia. Propomos, pois, uma maneira menos indutiva de formação e produção do conhecimento, com a sugestão de um sistema colaborativo de avaliação. $\mathrm{O}$ objetivo deste constructo é a parceria entre as partes envolvidas nos programas da pós-graduação brasileira, ou seja, uma visão mais universalizada e menos reducionista na qual o sujeito-docente é levado em consideração. Sendo assim, pode existir uma mudança paradigmática de distribuição de importância(s) entre ciência e humanidades, para então haver uma contribuição científica mais justa e equilibrada no desenvolvimento "do todo" social.

$\mathrm{O}$ incremento econômico também pode ocorrer por meio da pesquisa na universidade. Mas não pode se dar unicamente pela investigação científico-econômica, porque há o perigo de o meio acadêmico transformar-se em uma empresa e, desse modo, adotar seus regimes de gestão, distanciando-se da proposta crítico-formativa docente (Goergen, 2010). A racionalidade científica instrumental, produzida pela construção do conhecimento na civilização para "evitar" a barbárie, pode servir também para o contrário, como adverte Adorno (1995). Ou seja, o espírito pode ficar refém de sua própria criação, pelo modo utilitário de uso do poder. As regras baseadas no desenvolvimento econômico e na competitividade demonstram a incapacidade do reconhecimento do outro em uma busca de entendimento e verdade. A visão avaliativa da tecnologia baseada no viés da economia instrumental determina o "sujeito" como uma "estatística" ou produto. As estatísticas, porém, não podem determinar o sujeito-pesquisador em sua formação cultural, nem tampouco os principais objetivos do Estado avaliador como estrutura social. Senão, incorrem no erro de determinar o pesquisador subjetivamente como um meio econômico de desenvolvimento enquanto parte da estrutura de organização do Estado. 
Segundo o olhar crítico da filosofia da educação, se os objetivos da pesquisa acadêmica na pós-graduação brasileira estiverem reduzidos ao lema estatal de produzir para atender ao mercado econômico-empresarial, então se estarão reduzindo as possibilidades do seu universo, portanto a formação do sujeito consciente-de-si. Os docentes, ao cumprir sem crítica as regras de avaliação do Estado, executam planos, alcançam metas, melhoram rankings e demandam mão-de-obra para o mercado. Sendo assim, pela pressão das políticas avaliativas, abrem mão da construção colaborativa de objetivos (trans)formadores da sociedade.

\section{REFERÊNCIAS}

ADORNO, T. W. Educação e emancipação. Rio de Janeiro: Paz e Terra, 1995.

GOERGEN, P. Educação instrumental e formação cidadã: observações críticas sobre a pertinência social da universidade. Educar, Curitiba, n. 37, p. 59-76, maio/ago. 2010. http://dx.doi.org/10.1590/S0104-40602010000200005

GOERGEN, P.Tecnociência, pensamento e formação na educação superior. Avaliação (Campinas), Sorocaba, v. 19, n. 3, p. 561-584, nov. 2014. http://dx.doi.org/10.1590/ S1414-40772014000300003

GOMES, L. R. Educação, consenso e emancipação na teoria da ação comunicativa de Habermas. Publicatio: Ciências Humanas Linguística, Letras e Artes, Ponta Grossa, v. 15, n. 2, p. 53-63, 2007. https://doi.org/10.5212/publ.humanas.v15i2.602

HABERMAS, J. Técnica e ciência como ideologia. Tradução de Artur Mourão. Lisboa: Edições 70, 1968.

HABERMAS, J. A ideia de universidade: processos de aprendizagem. Revista Brasileira de Estudos Pedagógicos, Brasília, v. 74, n. 176, p. 111-113, jan./abr. 1993. http://dx.doi. org/10.24109/2176-6681.rbep.74i176.1217

HABERMAS, J. Teoría de la acción comunicativa I: racionalidad de la acción y racionalización social. Madrid: Taurus, 1999.

HABERMAS, J. Verdade e justificação: ensaios filosóficos. Tradução de Milton Camargo Mota. São Paulo: Loyola, 2004.

HEGEL, G. W. F. Fenomenologia do espírito. 2. ed. Tradução de Paulo Menezes e Karl-Heinz Efken. Rio de Janeiro: Editora Vozes, 1992.

HONNETH, A. Luta por reconhecimento: a gramática moral dos conflitos sociais. Tradução de Luiz Repa. São Paulo: Editora 34, 2003.

HONNETH, A. Reificación: un estudio en la teoría de reconocimiento. Tradução de Graciela Calderón. Buenos Aires: Editora Katz, 2007.

HONNETH, A. Observações sobre a reificação. Civitas Revista de Ciências Sociais, Porto Alegre, v. 8, n. 1, p. 68-79, out. 2008. http://dx.doi.org/10.15448/19847289.2008.1.4322

HONNETH, A. Barbarizações do conflito social: lutas por reconhecimento ao início do século 21. Civitas Revista de Ciências Sociais, Porto Alegre, v. 14, n. 1, p. 154-176, abr. 2014. http://dx.doi.org/10.15448/1984-7289.2014.1.16941 
LUKÁCS, G. História e consciência de classe: estudos sobre a dialética marxista. Tradução de Rodnei Nascimento. São Paulo: Martins Fontes, 2003.

\section{SOBRE OS AUTORES}

Amarildo Luiz Trevisan é doutor em educação pela Universidade Federal do Rio Grande do Sul (UFRGS). Professor da Universidade Federal de Santa Maria (UFSM).

E-mail: amarildo1.trevisan@gmail.com

Evandro Dotto Dias é doutor em educação pela Universidade Federal de Santa Maria (UFSM). Servidor Técnico Administrativo da Universidade Federal de Pelotas (UFPel).

E-mail: evandrodotto@yahoo.com.br

Iara da Silva Ferrão é doutoranda em educação pela Universidade Federal de Santa Maria (UFSM).

E-mail: iaraferrao@hotmail.com

Recebido em 26 de junbo de 2019

Aprovado em 26 de setembro de 2019 